\title{
Specificity of Early Categorial Thinking in Ancient China
}

\author{
Natalya Pushkarskaya \\ Center for Chinese Studies \\ Institute of Oriental Studies of the Russian Academy of Sciences \\ Moscow, Russia \\ E-mail: su-u@yandex.ru
}

\begin{abstract}
The article is dedicated to the universality problem in early categorial thinking of Ancient China. Universal conceptual schemes generated in archaic cultures appear to be an important part of contemporary science.
\end{abstract}

Keywords-universality; categorial thinking of Ancient China; fivefold conceptual scheme; binary conceptual scheme; Chinese traditional medicine; homeostasis

\section{INTRODUCTION}

Chinese culture is unique with its long continuous history and its unceasing interest to native traditions, carefully handed down from generation to generation. But what can our modern era of technological innovation and information technologies have in common with the distant semi-mythical time of the iconic legendary Chinese sages? What is it exactly that wise older generations so carefully hand down to their descendants? Is there any deep core around which all the notions of Chinese culture are built? Yes, there is indeed. The core, a vast body of traditional views and values, formed several centuries before Common Eraduring the Axial Age when people in different parts of the Earth, including Ancient China and Ancient Greece made attempts to describe the world rationally. The universal conceptual scheme, formed in the early period of categorial thinking in archaic China, became one of the crucial components of traditional Chinese culture, the core defining its identity. Created in the remote past, it proved to be able to survive all the disasters occurring in Chinese society, successfully adapted to the current cultural conditions, and now continues to communicate ancient imagery to the new generations.

\section{UNIVERS ALITY OF ARCHAIC FORMS OF CATEGORIAL THINKING}

According to the main representatives of German philosophy, I. Kant and M. Heidegger, the determinative characteristics of categorial thinking are apriority and extreme generality of the notions it operates. [1. P. 838], [2. P. 65]. The four basic elements (Water, Air, Fire, and Earth) of the early Greek philosophy are examples of such notions. In China, they are represented by so-called basic conceptual schemes: binary (yin-yang 阴阳), ternary (san cai 三材, 'the three spheres of origin' represented by the trinity of Heaven, Earth and Man), and the fivefold (wu xing 五行 'five elements' - Water, Fire, Wood, Earth and Metal) [3] "Fig. 1". These schemes represent the basic conceptual structures, which provide the basis for less general notions describing the human being and the world.

Fire 火-South 南-Summer 夏

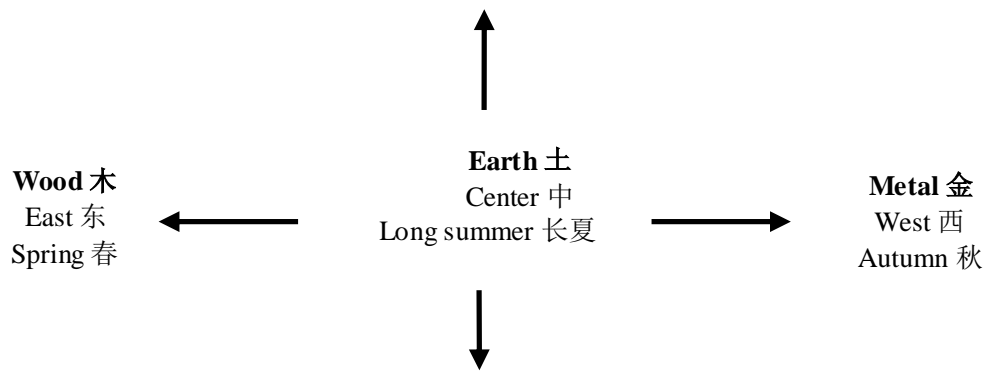

Water 水 - North 北 - Winter 冬

Fig. 1. The correlation between the Fire Elements, four seasons, and four directions. 
Despite several superficial differences, Chinese five elements and the four elements of the early Greek philosophy are very similar functionally and structurally. First of all, they both have the status of categorial notions. As for the structure, the numerical similarity is obvious: five elements are conceived as four elements plus the central element. Therefore, the specific character of the central fifth element is of a crucial importance. The fifth element of the fivefold conceptual scheme has a particular 'void' status, and the scheme itself correlates with four directions and four seasons. Although Greek elements are normally understood substantially, while the Chinese ones - mainly relationally, there are relational elements in the Greek conceptions as well: according to the Presocratics, the internal structure of the four elements is determined by the relation of contradiction.

The fourfold and fivefold conceptual schemes are universal not only because they are present in archaic cultures of the ancient world. Having once given birth to scientific thinking, these conceptual schemes are still with us, albeit their relevance might seem questionable. While the fivefold scheme is possible to discern in contemporary Chinese culture, to the eye of the present-day Western culture the whole fourfold/fivefold thing looks completely anachronistic.

However, if we take a closer look at the origins of Western and Chinese science, we will ascertain that rational thinking in these civilizations had been developing more or less in a similar way at least before the Modern era. According to Joseph Needham, a prominent British researcher of Chinese science, doctrines created during the era of early categorial thinking and based on the notions of the world's continuity and orderliness were flourishing in Medieval Europe, as well as in Medieval China. In his research, Needham came to the conclusion that Medieval China already had analogs of what later enabled Western scientists to create the new science. In his opinion, "the neoConfucian speculative thought and subtle methods of the experimentation technique' [5. P. 142] were analogous to European scholastics and experimentation. It was not until the modern era, which had given rise to experimental method in natural sciences, that Chinese and Western science became completely different. 'When Galileo's work appeared, organic perception of the world as complete and hierarchically ordered was destroyed' [5. P. 140] Therefore, it can be argued that in the late Medieval times China and Europe shared common thought patterns and prerequisites for establishing the so-called modern science (and that experimental natural science did not emerge in China for some social reasons and not because of the manner in which Chinese thought was developing.)

The further development of Western science was so obviously different from the way Chinese science evolved that researchers have no doubt: European thought made a revolutionary leap, while Chinese scientific thinking stayed within ancient categorial structures.

Nevertheless, we keep finding multiple justifications to our supposition about universality of the early forms of rational thinking, this time in contemporary Western science.
It should be noted that while in Chinese culture such persistence of the archaic elements could be explained by its inherent conservatism and proneness to stagnation, we are yet to find a proper explanation for the same phenomena occurring in Western culture of the XX century, for we cannot attribute them to a stagnant mentality.

But first we are going to have a look at Chinese culture and discuss the ways the universal conceptual structure of Ancient China reveals itself in Chinese traditional medicine.

\section{THE System OF BASIC CONCEPTUAL SCHEMES IN ChINESE TRADITIONAL MEDICINE}

The universal notions in question are particularly relevant in contemporary Chinese culture. As previously mentioned, the core of Chinese culture since ancient times has been the body of traditional views involving such universal categorial schemes as the fundamental yin/yang opposition, the five elements of wu xing, and the san cai unity of Heaven, Earth and Man. Chinese traditional medicine, which is still meaningful nowadays and not only in China, serves as a perfect example of historical continuity and reveals some striking correspondence with discoveries of Western science.

I will cite briefly the basic principles of Chinese traditional medicine. The most comprehensive account of the basics of Chinese medicine can be found in Huangdi Neijing 黄帝内经 (The Inner Canon of the Yellow Emperor), also known as the Neijing 内经 (The Inner Canon) [6]. This corpus of medical texts is one of the most ancient in China. The source is thought to have been compiled during the Western Han or Former Han period (about 202 BC - 8 AD). It had been preceded by a long history of medical theories and practices, not recorded systematically, based (as well as Chinese culture in general) on the principles of The Book Of Changes, centered around the yin-yang juxtaposition represented by broken and unbroken lines of the hexagrams. The ideas set forth in The Book Of Changes constitute the deepest layers of Chinese worldview, and this applies to the present time as well.

The importance of understanding the relationship between yin and yang and using the forces correctly is treated in the Neijing in connection with the story of ancient Taoist hermits striving to achieve immortality. They were keen on maintaining physical health, curing diseases, and the interest in their practices is alive nowadays.

In the Part I of the Neijing, in the chapter titled 'Discourse on the True [Qi Endowed by] Heaven in High Antiquity' the Yellow Emperor says: "I have heard, in high antiquity there were true men. They upheld [the patterns of] heaven and earth and they grasped [the regularity of] yin and yang. They exhaled and inhaled essence qi. They stood for themselves and guarded their spirit.Muscles and flesh were like one. Hence, they were able to achieve longevity, in correspondence with heaven and earth. There was no point in time when [their life could have] come to an end. Such was their life in the Way."

The knowledge of 'the patterns of heaven and earth and the regularity of yin and yang' is put first, because all further 
practices aimed to achieve physical health and longevity are futile without deep understanding of interaction of these elements.

The main point is that the universe as a whole, as well as all its components, is described as containing the two basic opposite qualities: passive, negative, weak and destructive yin and active, positive, strong and constructive yang. Every object, process or quality can be described using these two notions as potentially having two extremes, two diametrically opposite manifestations. Speaking about human body, we can mention opposites such as internal/external, emptiness/fullness, male/female, heat/cold, movement/stillness. For instance, inhalation/exhalation are the extreme manifestations of the same phenomenon, in this case, breathing; heat and cold are the highest and the lowest temperatures, and so on [7. P. 63]. All the antagonistic manifestations of any process are counterpoised, maintaining the balance between all sophisticated chemical and physical interactions inside the human body. It means that if the ratio is right, the opposite elements are simultaneously present.

Normally, both yin and yang contain a small portion of the opposite element. Lack or over-abundance of any of the two disrupts the balance and results in disease, which can lead to death. One cannot live unless the opposite elements are balanced. In some cases, human body is capable of overcoming the imbalance by itself. When it fails, some external help is required, and while providing it, according to Chinese medicine, it is crucial to understand which body parts correlate with yin or yang, to reinforce or weaken them accordingly in order to reestablish the balance.

Thus it is possible to conclude that the main principle of Chinese medicine is counteraction. (If we recall the homeopathy basic doctrine of 'like cures like', it will seem obvious that at least from Chinese medicine viewpoint homeopathy is useless.)

It is also worth noticing that macrocosm and microcosm are closely related: fundamental laws of the universe take effect inside the human body as well; human beings are not separate entities but parts of nature. The ternary conceptual scheme known as 'san tsai' consolidates the notion of man being inseparably linked with the environment and the cosmos.

As for the five elements theory (wu xing), it undoubtedly exists in the framework of the yin-yang conception and its main principle, providing insights into relationship between man and nature. As mentioned above, within the five elements theory man or the world are described not only in terms of interaction between two opposite forces, but as a whole represented by five interconnected parts.

As applied to man, the fivefold conceptual scheme in Chinese medicine is normally used while describing internal organs. The five viscera wu tsang 五脏 correspond to the five elements of wu xing 五行; their relationship is regarded as a part of the universal processes of mutual overcoming xiang ke 相克 and mutual generation xiang sheng 相生 that constantly unfold in the nature and in any separate organism.
Observing changes in nature and the corresponding human activities enabled Chinese thinkers to identify recurring cycles of interactions between substances and materials. In the overcoming cycle xiang ke 相克, Wood parts Earth, Earth dams Water, Water extinguishes Fire, Fire melts Metal, Metal chops Wood. In the generating cycle xiang sheng 相生,Wood feeds Fire, Fire creates Earth, Earth bears Metal, Metal collects Water, Water nourishes Wood. According to traditional Chinese medicine, similar interactions take place between internal organs. Heart xīn 心, Liver gān 肝, Spleen pí 脾, Lung feì 肺, Kidney shèn 肾 correspond to Fire huǒ 火, Wood mù 木, Earth tǔ 土, Metal jīn 金, and Water shuǐ 水 respectively “Fig. 2". Mutual influence of the internal organs reinforces the balance between them and balance all the vital systems.

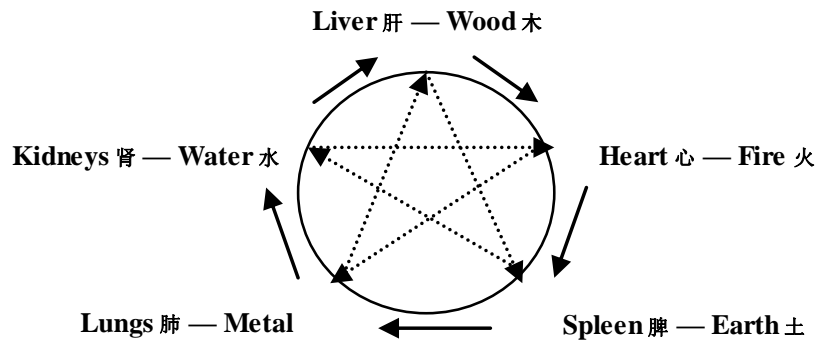

Fig. 2. Generating and overcoming cycles of the five elements and the five viscera.

Thus, the Neijing says that the internal organs function according to the juxtaposition principle of yin-yang.

Apart from the processes taking place inside the human body, the Neijing takes into close consideration effects of the environment on one's health. It involves the four directions sì fang 四方, the four seasons sì shí 四时, the five natural phenomena wǔ zhēng 五征 and the five flavors wǔ wèi 五味.

As I mentioned before, the Five Elements are conceived as Four Elements plus the central element, so the fourfold scheme can be referred to as the shortened version of the fivefold one. Therefore, the four directions (sì fang 四方) and the four seasons (sì shí 四 时) exemplify basic correlations with the five elements of wu xing.

Human is greatly affected by the four seasons. In spring and summer, we see the reproductive and growth functions intensify, while autumn and winter fulfill the task of maintaining the structure [7. P. 82]. Internal organs coexist with the environment in the same harmonized pace, and their functioning is similar.

All these complex interrelated processes going on in the human body are, as viewed by nameless Chinese sages, the reflection of universal processes going on in the surrounding world. The way natural forces interact in the greater picture is not different from the way they interact inside the human body. The balanced work of the complex system that is a living creature and the balance of natural forces are the crucial condition of a fulfilling life, and moreover - of life as such. Centuries ago, the ancient Chinese were able to record and pass on to the present time their wonderful insights into 
the human existence in this world. Since the ancient times and until today, they have tenaciously adhered to the holistic perspective of reality. And now, we can witness their allegedly primitive speculations strike chord with modern science.

\section{THE Notion OF HoMEOSTASIS}

The notion of homeostasis (from ancient Greek ö $\mu$ oro $\varsigma$

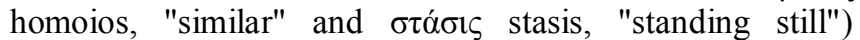
popular with the modern Western medicine describes the ability of living systems to reproduce themselves and autonomously sustain the balance needed for survival.

The 19th century French physiologist Claude Bernard (1813-1878) noticed that the body itself was able to maintain the constancy of the things it requires for normal functioning. $\mathrm{He}$ introduced the concept milieu interieur (internal environment) and noted that the maintenance of the internal environment was essential for the life of the organism [8].

In 1932, American physiologist Walter Cannon (18711945) in his work The Wisdom of the Body developed Bernard's idea and coined the term homeostasis to refer to the complex mechanism of maintaining the static conditions of the internal environment of the organism [9].

Norbert Wiener (1894-1964), a prominent mathematician and the father of cybernetics, built on the concept of homeostasis and discovered that negative feedback (!) was the main mechanism of homeostasis control and regulation (compare this with the principle of yin-yang). By the way, the negative feedback principle went on to become essential in the creation of complex control systems for computers [10].

"In homeostasis, we can see a principle common to both Western and traditional Chinese medicine" [7. P. 60] The mechanisms of maintaining the "internal environment" of the body opened by Western scientists correlate perfectly with the ideas of Chinese medicine developed long before the Modern Era.

And so, the question arises: how is it possible that the obsolete worldviews which seem to have been discarded by the progressive humanity continue to crop up in contemporary scientific work? Could it be that these constructs are not necessarily so archaic as not to have anything in common with today's reality?

\section{CONCLUSION}

Coincidences in the views of Chinese traditional medicine and Western science might seem startling but are quite explainable. Lack of a powerful scientific body of evidence does not yet mean the entire line of though is wrong. The rationality of human cognition is universal, differing only in research methods. The ability of human mind to capture the essence of phenomena allows it to build universal conceptual systems which never cease to be relevant. The Chinese basic categorial system is by all means one of such.

\section{REFERENCES}

[1] Immanuel Kant, The Critique of Pure Reason, the 1st edition. Appendix: The Critique of Pure Reason, Minsk, Literatura, 1998.

[2] Martin Heidegger, Nietzsche, Band 2, Saint-Petersburg, Vladimir Dal', 2007.

[3] Krushinskiy A.A., Logic of concept formation in ancient China, Vostok, 2006, No.5, pp. 5-22.

[4] Pushkarskaya N.V., For the problem of yearly categorical thinking, Philosophy and Culture, 2016, No. 10, pp.1430-1441. DOI: 10.7256/1999-2793.2016.10.10407.

[5] Needham D., Mathematics and science in China and in the Western world, Moscow, 1977.

[6] Huangdi Neijing, (The Yellow Emperor's Inner Canon), URL:http://www.gushiwen.org/guwen/huanglei.aspx (accessed date 04/16/2017).

[7] Wei Tsuei, Roots of Chinese Culture and Medicine, Chinese Culture Books Co., Oakland, California, U.S.A., 1989.

[8] Bernard C., Lectures on experimental pathology, Biomedgiz, Moscow, Leningrad, 1937.

[9] Cannon W.B., The Wisdom of the body, Norton, New York, 1963.

[10] Viner N., Cybernetics, or Control and communication in the animal and machine, 2nd edition, Moscow, Sovetskoe radio, 1968. 